\title{
Psychological wellbeing and biochemical modulation in response to weight loss in obese type 2 diabetes patients
}

\author{
Al-Jiffri Osama ${ }^{1}$, Abd El-Kader Shehab ${ }^{2}$
}

\begin{abstract}
1. Department of Medical Laboratory Technology, Faculty of Applied Medical Sciences, King Abdulaziz University.

2. Department of Physical therapy, Faculty of Applied Medical Sciences, King Abdulaziz University.
\end{abstract}

\begin{abstract}
Background: Obesity in type 2 diabetes patients is a serious health issue by itself; it is also associated with other health problems including psychiatric illnesses. The psychological effects of dieting and weight loss have been a matter of controversy in the field of obesity management.

Objective: The aim of this study was to compare the impact of weight loss because of aerobic exercise training and dietary measures on psychological wellbeing and biochemical modulation in obese type 2 diabetes patients.

Material and methods: One hundred obese type 2 diabetes patients of both sexes participated in this study, and were included into two equal groups. The first group (A) received aerobic exercise training, three sessions per week for three months combined with dietary measures. The second group (B) received no training intervention for three months.

Results: There was a significant decrease in body mass index (BMI), leptin, total cholesterol (TC), low density lipoprotein cholesterol (LDL-c), triglycerides(TG), homeostasis model assessment-insulin resistance- index (HOMA-IR), beck depression inventory (BDI) \& profile of mood states(POMS) and increase in high density lipoprotein cholesterol (HDL-c) \& Rosenberg self-esteem scale (RSES) of group (A) after treatments, but the changes of group (B) were not significant. Moreover, there were significant differences between mean levels of the investigated parameters of group (B) and group (A) at the end of the study.

Conclusion: Physical training and dietary measures can be used as methods of choice for psychological wellbeing and biochemical modulation in obese type 2 diabetes patients.
\end{abstract}

Keywords: Obesity; type 2 diabetes, aerobic exercise training, dietary measures, psychological wellbeing.

DOI: http://dx.doi.org/10.4314/ahs.v15i2.25

\section{Introduction}

The global prevalence of type 2 diabetes has been rising steadily over the past 3 decades, and is largely attributable to the dramatic increase in obesity rate ${ }^{1,2}$. Over 300 million people worldwide live with diabetes now, and if the current prevalence rate continues unabated, over 550 million people will be living with diabetes by $2030^{3,4 .}$ Diabetes represents a major health problem be-

\section{Corresponding author:}

Abd El-Kader Shehab,

Faculty of Applied Medical Sciences,

Department of Physical Therapy,

King Abdulaziz University,

P.O. Box 80324, Jeddah, 21589,

Saudi Arabia.

Email: salmuzain@kau.edu.sa cause of its high prevalence, morbidity and mortality, its influence on patient quality of life, and its impact on the health system ${ }^{5}$. It is now widely accepted that the obesity epidemic continues to be the principal driver for the rising global prevalence of type 2 diabetes mellitus ${ }^{6}$, cardiovascular disease, musculoskeletal disease, cancers and all-cause mortality ${ }^{7}$.

Type 2 diabetes mellitus is a serious chronic disease whereby the body is unable to effectively use glucose as a fuel due to relative insulin deficiency caused by insulin resistance ${ }^{8}$. Untreated acute and chronic states of hyperglycemia could lead to debilitating long-term complications. Heart attacks and strokes are two to three fold higher in people with diabetes, along with increased risks for retinopathy, nephropathy and neuropathy. Life expectancy can be shortened by as much as 10-15 years because of premature and accelerated atherosclerosis, and the attendant medical complications? 
Depression is a health complication that is commonly associated with obesity as risk of depression is $20-50 \%$ higher among obese individuals than normal weigh persons ${ }^{10,11}$. Extremely obese persons are at even greate risk $^{12}$. The relationship between obesity and depression appears to be bi-directional; some longitudinal studies have shown that depression is associated with subsequent weight gain and obesity ${ }^{13-15}$, whereas others have found that obesity is associated with the development of depression ${ }^{16,17}$.

As the lifetime risk of diabetes increases substantially and proportionally with the magnitude of overweigh and obesity ${ }^{18}$, a major effort of the fight against diabetes is focused on diabetes prevention through weight loss and health behavior changes, and aggressive glycemic and overall management of diabetes to prevent the deadly complications ${ }^{18,19}$. However, health behavior modification, aiming at achieving a healthier body weight through dietary therapy and regular physical activity, is the cornerstone therapy for people with diabetes recommended by the American Diabetes Association ${ }^{20}$. The 2013 American Diabetes Association standards of medical care in diabetes guidelines recommend a 7\% body weight loss for all overweight or obese individuals who have or are at risk for diabetes through dietary strategies and regular physical activity ${ }^{21}$. Physical activity combined with calorie restriction improves no only parameters of well-being and prevention of majo morbidity but also embeds longer-term weight maintenance ${ }^{22,23}$.

The aim of this study was to measure the impact of weight loss because of aerobic exercise training and dietary measures on psychological wellbeing and biochem ical modulation in obese type 2 diabetes patients

\section{Patients and methods}

\section{Subjects} One hundred obese type 2 diabetes patients of both tecubital vein while patients rested in a supine position. Aziz University hospital and other hospitals at Jeddah $\quad(1000=\mathrm{g}$ for $10 \mathrm{~min})$. Plasma sample with K2EDTA area. Their age was between $35-45$ years, the body mass $\quad$ was collected after centrifugation $(2000 \times \mathrm{g}$ for $10 \mathrm{~min}$ index (BMI) ranged from 32 to $36 \mathrm{Kg} / \mathrm{m} 2$, free from at $4^{\circ} \mathrm{C}$ ) and stored at $-80^{\circ} \mathrm{C}$ to analyze leptin, total choother co-morbidities as respiratory, kidney, liver, neu- lesterol, triacylglycerol, high-density lipoprotein cholesrological disorders and orthopedic problems inhibiting terol, low-density lipoprotein cholesterol. All analyses treadmill training or renal disease. Participants were in- were carried out on a Hitachi 7170 Autoanalyser (Tocluded into two equal groups; the first group (A) re- kyo, Japan) or with commercial kits (Randox). Also, kit ceived aerobic exercise training, three sessions per week (Bioclin, Quibasa, Belo Horizonte, MG, Brazil) were

\section{Psychological well-being}

Data was collected at baseline and at the end of treatment. Participants were asked to attend two laboratory sessions in order to complete all psychological assessments, in each evaluation period. Self-esteem was assessed with the Rosenberg self-esteem scale (RSES), a 10 -item scale that measures global self-worth by measuring both positive and negative feelings about the self. The scale is believed to be unidimensional. All items are answered using a 4-point Likert scale format ranging from strongly agree to strongly disagree. Mood disturbance was assessed with the profile of mood states (POMS). Originally, the POMS included sixty five items which load on seven different scales: "depression", "anxiety", "fatigue", "vigour", "irritability", "tension", and "confusion". The questions refer to the time period of the "last week including today". The response scale is divided into five categories ranging from "not at all" to "very strong". The items are defined from 1 to 5 ("not at all", "a little", "moderately", "quite a bit", and "extremely", respectively). The questionnaire assessed six dimensions of mood that can be used to calculate a total mood disturbance score, which was used in the present study. Questions pertain to emotional states of the previous month. Depression was evaluated with the Beck depression inventory (BDI), a 21 -item inventory measuring several symptoms of depression. It uses a 4-point ordered scale and results in a total score (Items 1 - 3 assess symptoms that are psychological in nature, while items 14 - 21 assess more physical symptoms. This was rated as follows: 1 - 10: Normal: 11 - 16: Mild mood disturbance; 17 - 20: Borderline clinical depression; 21 30: Moderate depression and $>30$ : Severe depression) ${ }^{24}$.

3. Evaluation of anthropometric parameters All measurements were performed at pretreatment and after three months at the end of the study. The participants were measured whilst wearing their undergarments and hospital gowns. Height was measured with a digital stadiometer to the nearest $0.1 \mathrm{~cm}$ (JENIX DS 102, Dongsang, South Korea). Body weight was measured on a calibrated balance scale to the nearest $0.1 \mathrm{~kg}$ (HC4211, Cas Korea, South Korea), and body mas index (BMI) was calculated as BMI $=$ Body weight $/$ $(\text { Height })^{2}$.
All measurements of leptin, total cholesterol, triacylgycerol, high-density lipoprotein cholesterol, low-density lipoprotein cholesterol, BMI, HOMA-IR, BDI and POMS were taken before the starting of the study (pretest) and after three months at the end of the study (post-test).

\section{Procedures}

Following the previous evaluation, all patients were divided randomly into the following groups:

1. Patients in Group (A) were submitted to forty minutes moderate intensity aerobic exercise session on a treadmill (the initial, 5-minute warm-up phase performed on the treadmill (Enraf Nonium, Model display panel Standard, NR 1475.801, Holland) at a low load, each training session lasted 30 minutes and ended with 5-minute recovery and relaxation phase) either walking or running, based on heart rate, until the target heart rate was reached, according to American College of Sport Medicine guidelines ${ }^{25}$. The program begun with 10 min of stretching and was conducted using the maximal heart rate index (HRmax) estimated by 220-age. First 2 weeks $=60-70 \%$ of HRmax, 3rd to 12th weeks $=70-80 \%$ of HRmax. Each session was continued for 30 minutes; 3 sessions / week for 3 months ${ }^{26}$.

All subjects of group (A) were instructed to take an individual balanced energy-restricted dietary program to obtain weight loss .The mean daily caloric intake was about1200 kcal/day based on a macronutrient content $<30 \%$ fat and $15 \%$ protein as recommended by the World Health Organization ${ }^{27}$. At the initial interview with a dietitian, obese subjects was given verbal and written instructions on how to keep diet records, with food weighed and measured. Dietary intake was monitored by the same dietitian. The subjects maintained a detailed record of food intake, and received weekly nutritional counseling. Obese subjects were instructed to substitute low-fat alternatives for typical high-fat foods, to increase the consumption of vegetables and fresh fruits, and to substitute complex carbohydrates, such as whole-grain bread and cereals. Dietetic help was given every 2 weeks by the dietitian when anthropometric measurements were performed; in addition, each subject was seen by a physician monthly to perform a clinical evaluation, standard electrocardiogram, and measurement of blood pressure and heart rate ${ }^{26,28}$ 
2. Patients in Group (B) received no training or diet paired " $\mathrm{t}$ " test. Independent " $\mathrm{t}$ " test was used for the regimen for three months.

Statistical analysis

Results

The mean values of BMI, Leptin, TC, HDL-c, LDL-c, The two groups were considered homogeneous regardTG, RSES, BDI and POMS obtained before and af- ing the baseline characteristics (Table 1).

ter three months in both groups were compared using

Table (1): Demonstrates the baseline characteristics of all participants.

\begin{tabular}{|l|c|c|c|}
\hline \multirow{2}{*}{\multicolumn{1}{|c|}{ Parameters }} & \multicolumn{2}{c|}{ Mean \pm SD } & \multirow{2}{*}{ p value } \\
\cline { 2 - 3 } & Group A (N = 50) & Group B (N= 50) & \\
\hline Age (years) & $36.35 \pm 5.11$ & $37.16 \pm 4.32$ & $\mathrm{P}>0.05$ \\
\hline Waist circumference (cm) & $107.54 \pm 8.38$ & $106.18 \pm 7.13$ & $\mathrm{P}>0.05$ \\
\hline Hip circumference $(\mathrm{cm})$ & $113.17 \pm 7.82$ & $112.95 \pm 8.11$ & $\mathrm{P}>0.05$ \\
\hline Waist to hip ratio & $0.91 \pm 0.14$ & $0.89 \pm 0.13$ & $\mathrm{P}>0.05$ \\
\hline Body weight $(\mathrm{kg})$ & $94.26 \pm 8.27$ & $92.97 \pm 7.82$ & $\mathrm{P}>0.05$ \\
\hline $\begin{array}{l}\text { Systolic blood pressure } \\
\text { (mm Hg) }\end{array}$ & $142.16 \pm 10.54$ & $140.34 \pm 11.12$ & $\mathrm{P}>0.05$ \\
\hline $\begin{array}{l}\text { Diastolic blood pressure } \\
\text { (mm Hg) }\end{array}$ & $87.13 \pm 8.23$ & $85.15 \pm 7.21$ & $\mathrm{P}>0.05$ \\
\hline Fasting glucose (mg/dl) & $128.37 \pm 10.18$ & $127.87 \pm 9.87$ & $\mathrm{P}>0.05$ \\
\hline HbA1c \% & $7.93 \pm 1.86$ & $7.26 \pm 1.55$ & $\mathrm{P}>0.05$ \\
\hline Total cholesterol $(\mathrm{mg} / \mathrm{dl})$ & $192.30 \pm 12.86$ & $193.54 \pm 11.22$ & $\mathrm{P}>0.05$ \\
\hline HDL-cholesterol $(\mathrm{mg} / \mathrm{dl})$ & $34.54 \pm 2.71$ & $33.73 \pm 2.95$ & $\mathrm{P}>0.05$ \\
\hline LDL-cholesterol $(\mathrm{mg} / \mathrm{dl})$ & $132.93 \pm 9.78$ & $133.64 \pm 9.03$ & $\mathrm{P}>0.05$ \\
\hline Triglyceride $(\mathrm{mg} / \mathrm{dl})$ & $154.15 \pm 10.21$ & $155.18 \pm 9.82$ & $\mathrm{P}>0.05$ \\
\hline
\end{tabular}

MI = Body Mass Index; HbA1c $=$ Hemoglobin A1C; $\mathrm{HDL}=$ High Density Lipoprotein; $\mathrm{LDL}=$ Low Density Lipoprotein

There was a significant decrease in body mass index of mood states(POMS) and increase in high density (BMI), leptin, total cholesterol (TC), low density lipo- lipoprotein cholesterol (HDL-c) \& Rosenberg self-esprotein cholesterol (LDL-c), triglycerides(TG), home- teem scale (RSES) of group (A) after treatments (Table ostasis model assessmentinsulin resistance- index ( $\mathrm{HO}-2$ 2), but the changes of group (B) were not significan MA-IR), Beck depression inventory (BDI) \& profile (Table 3).
Table (2): Mean value and significance of BMI, Leptin, TC, HDL-c, LDL-c, TG, HOMAR, RSES, BDI and POMS of group (A) before and after treatment.

\begin{tabular}{|l|c|c|c|c|}
\hline \multirow{2}{*}{} & \multicolumn{2}{|c|}{ Mean \pm SD } & \multirow{2}{*}{ T-value } & P-value \\
\cline { 2 - 3 } & Before & After & & \\
\hline BMI (Kg/m $\mathbf{2})$ & $32.86 \pm 5.29$ & $30.13 \pm 4.32$ & 5.26 & $\mathrm{P}<0.05$ \\
\hline Leptin (Ng/mI) & $39.72 \pm 5.75$ & $36.21 \pm 5.195$ & 6.31 & $\mathrm{P}<0.05$ \\
\hline TC $(\mathbf{m g} / \mathbf{d l})$ & $192.30 \pm 12.86$ & $176.54 \pm 11.66$ & 9.75 & $\mathrm{P}<0.05$ \\
\hline HDL-c (mg/dl) & $34.54 \pm 2.71$ & $36.35 \pm 2.48$ & 6.24 & $\mathrm{P}<0.05$ \\
\hline LDL-c (mg/dl) & $132.93 \pm 9.78$ & $120.27 \pm 8.94$ & 7.22 & $\mathrm{P}<0.05$ \\
\hline TG (mg/dI) & $154.15 \pm 10.21$ & $129.61 \pm 9.83$ & 8.35 & $\mathrm{P}<0.05$ \\
\hline HOMA-IR & $7.21 \pm 2.13$ & $5.65 \pm 1.94$ & 4.31 & $\mathrm{P}<0.05$ \\
\hline Self-esteem (RSES) & $21.12 \pm 3.45$ & $26.73 \pm 3.22$ & 5.61 & $\mathrm{P}<0.05$ \\
\hline Depression (BDI) & $7.98 \pm 2.05$ & $5.21 \pm 1.97$ & 3.32 & $\mathrm{P}<0.05$ \\
\hline $\begin{array}{l}\text { Total mood disturbance } \\
\text { (POMS) }\end{array}$ & $23.95 \pm 4.42$ & $19.61 \pm 4.13$ & 5.11 & $\mathrm{P}<0.05$ \\
\hline
\end{tabular}

MI = Body Mass index; TC $=$ Total cholesterol; HDL-c $=$ High-density lipoprotein cholesterol; LDL$\mathrm{c}=$ Low-density lipoprotein cholesterol; $\mathrm{TG}=$ Triglyceride; $\quad$ HOMA-IR $=$ Homeostasis Model Assessment-Insulin Resistance Index; RSES = Rosenberg Self-Esteem Scale; BDI = Beck Depression Inventory; POMS = Profile of Mood States

Table (3): Mean value and significance of BMI, Leptin, TC, HDL-c, LDL-c, TG, HOMA-IR, RSES, BDI and POMS of group (B) before and after treatment.

\begin{tabular}{|c|c|c|c|c|}
\hline & \multicolumn{2}{|c|}{ Mean \pm SD } & \multirow{2}{*}{$\begin{array}{c}\text { T- } \\
\text { value }\end{array}$} & \multirow[t]{2}{*}{ P-value } \\
\hline & Before & After & & \\
\hline BMI $\left(\mathrm{Kg} / \mathrm{m}^{2}\right)$ & $33.15 \pm 4.87$ & $33.45 \pm 4.16$ & 0.82 & $\mathrm{P}>0.05$ \\
\hline Leptin (Ng/ml) & $38.64 \pm 5.16$ & $38.91 \pm 4.37$ & 0.98 & $\mathrm{P}>0.05$ \\
\hline TC (mg/dl) & $193.54 \pm 11.22$ & $195.12 \pm 10.25$ & 1.25 & $\mathrm{P}>0.05$ \\
\hline HDL-c (mg/dl) & $33.73 \pm 2.95$ & $32.81 \pm 2.74$ & 0.89 & $\mathrm{P}>0.05$ \\
\hline LDL-c (mg/dl) & $133.64 \pm 9.03$ & $133.88 \pm 8.72$ & 0.95 & $\mathrm{P}>0.05$ \\
\hline TG (mg/dl) & $155.18 \pm 9.82$ & $156.11 \pm 9.23$ & 1.12 & $\mathrm{P}>0.05$ \\
\hline HOMA-IR & $7.53 \pm 2.32$ & $7.81 \pm 2.15$ & 0.81 & $\mathrm{P}>0.05$ \\
\hline Self-esteem (RSES) & $20.54 \pm 3.72$ & $19.82 \pm 3.43$ & 0.93 & $\mathrm{P}>0.05$ \\
\hline Depression (BDI) & $8.15 \pm 2.14$ & $8.41 \pm 2.11$ & 0.62 & $\mathrm{P}>0.05$ \\
\hline $\begin{array}{l}\text { Total mood disturbance } \\
\text { (POMS) }\end{array}$ & $24.04 \pm 4.31$ & $24.22 \pm 4.16$ & 0.86 & $\mathrm{P}>0.05$ \\
\hline
\end{tabular}

(POMS)

BMI $=$ Body Mass index; $\mathrm{TC}=$ Total cholesterol; HDL-c $=$ High-density lipoprotein cholesterol; LDL-c= Low-density lipoprotein cholesterol; $\mathrm{TG}=$ Triglyceride; $\quad$ HOMA-IR $=$ Homeostasis Model Assessment-Insulin Resistance Index; RSES = Rosenberg Self-Esteem Scale; BDI = Beck Depression
Inventory; POMS = Profile of Mood States. 
Table (4): Mean value and significance of BMI, Leptin, TC, HDL-c, LDL-c, TG, HOMAIR, RSES, BDI and POMS of group (A) and group (B) after treatment.

\begin{tabular}{|l|c|c|c|c|}
\hline \multirow{2}{*}{} & \multicolumn{2}{|c|}{ Mean \pm SD } & \multirow{2}{*}{ T-value } & P-value \\
\cline { 2 - 5 } & Group (A) & Group (B) & & \\
\hline BMI (Kg/m $\mathbf{2})$ & $30.13 \pm 4.32$ & $33.45 \pm 4.16$ & 4.75 & $\mathrm{P}<0.05$ \\
\hline Leptin (Ng/ml) & $36.21 \pm 5.195$ & $38.91 \pm 4.37$ & 5.62 & $\mathrm{P}<0.05$ \\
\hline TC (mg/dl) & $176.54 \pm 11.66$ & $195.12 \pm 10.25$ & 8.55 & $\mathrm{P}<0.05$ \\
\hline HDL-c (mg/d) & $36.35 \pm 2.48$ & $32.81 \pm 2.74$ & 5.42 & $\mathrm{P}<0.05$ \\
\hline LDL-c (mg/dl) & $120.27 \pm 8.94$ & $133.88 \pm 8.72$ & 6.34 & $\mathrm{P}<0.05$ \\
\hline TG (mg/dl) & $129.61 \pm 9.83$ & $156.11 \pm 9.23$ & 7.61 & $\mathrm{P}<0.05$ \\
\hline HOMA-IR & $5.65 \pm 1.94$ & $7.81 \pm 2.15$ & 3.45 & $\mathrm{P}<0.05$ \\
\hline Self-esteem (RSES) & $26.73 \pm 3.22$ & $19.82 \pm 3.43$ & 4.21 & $\mathrm{P}<0.05$ \\
\hline Depression (BDI) & $5.21 \pm 1.97$ & $8.41 \pm 2.11$ & 3.12 & $\mathrm{P}<0.05$ \\
\hline $\begin{array}{l}\text { Total mood disturbance } \\
\text { (POMS) }\end{array}$ & $19.61 \pm 4.13$ & $24.22 \pm 4.16$ & 4.10 & $\mathrm{P}<0.05$ \\
\hline
\end{tabular}

BMI $=$ Body Mass index; $\mathrm{TC}=$ Total cholesterol; HDL-c $=$ High-density lipoprotein cholesterol; LDL$\mathrm{c}=$ Low-density lipoprotein cholesterol; TG $=$ Triglyceride; $\quad$ HOMA-IR $=$ Homeostasis Model
Assessment-Insulin Resistance Index; RSES $=$ Rosenberg Self-Esteem Scale; BDI $=$ Beck Depression Inventory; POMS = Profile of Mood States.

Discussion

The psychological effects of dieting and weight loss have been a matter of controversy in the field of obesity management. Several early studies (before the 1970s) described negative emotional consequences to dieting ${ }^{29}$, whereas later studies found an improvement or no changes in the symptoms of depression, self-esteem, mood and anxiety in patients that are obese treated by behavior modification combined with moderate calorie restriction ${ }^{30-33}$. These conflicting results constitute an incentive to conduct our study to the impact of weight loss as a result of aerobic exercise training and dietary measures on psychological wellbeing and biochemical modulation in obese type 2 diabetes patients.

The findings of this study showed that weight loss because of aerobic exercise training and dietary measures by obese type 2 diabetic patients led to decreased BMI, Leptin, TC, LDL-c, TG\& HOMA-IR and increased HDL-c. Accumulating evidence confirms these findings indicates that lifestyle changes such as weight loss and regular physical activity are recognized as effective non-pharmacological interventions with beneficial effects and biochemical modulation in obese type 2 diabetes patients ${ }^{34-36}$.
Pi-Sunyer etal. found that an intensive lifestyle intervention for type 2 diabetes patients was associated with an average of $8.6 \%$ body weight loss compared with $0.7 \%$ in the diabetes support and education (control) group after one year, this was accompanied by an A1C reduction from $7.3 \%$ to $6.6 \%$, along with improved fitness level, blood pressure and lipid values. The weight changes were significantly correlated with changes in protein cholesterol, and triglycerides; larger weight los resulted in greater improvements in each of the cardiovascular risk factors ${ }^{34}$

Snel et al. included 27 obese type 2 diabetes patients in 16-week very low calorie diet and exercise program and found that a significant weight loss, glycemic control and major improvements in health-related quality of $\operatorname{life}^{35}$. Moreover, Jazet etal. applied a study on eighteen insulin-treated obese type 2 diabetes patients who wete followed for 18 months after they followed a 30-day very low calorie diet (VLCD, $450 \mathrm{k} \mathrm{Cal} /$ day) with the cessation of all glucose-lowering medication. After the 30-day VLCD, caloric intake was slowly increased and glucose-lowering medication was restarted if necessary. On day 0 and 30 of the VLCD and after 18 month follow-up, bodyweight, blood pressure, glycemic con- trol and lipid levels were measured. The 30-day VLCD significantly reduced bodyweight and waist circumference and improved dyslipidemia, hypertension and glycaemia $^{30}$

This study also showed weight loss because of aerobic exercise training and dietary measures by obese type 2 diabetes patients led to decreased Beck depression inventory (BDI) \& profile of mood states (POMS) and increased Rosenberg self-esteem Scale (RSES). In this regard, some studies revealed that the weight loss has a strong impact on psychological wellbeing in obese type 2 diabetes patients ${ }^{37-41}$.

Grave et al. investigated the effects of weight loss on psychological distress and binge eating in 500 patients that are obese of both sexes remaining in continuous treatment at different centers with slightly different strategies. At baseline and after 12 months all subjects were evaluated by the SymptomCheckList-90 Global Severity Index (SCL-GSI) and by the Binge eating scale (BES). In both males and females, weight loss was associated with improved psychometric testing of psychoogical distres $s^{37}$. However, in a systematic review of 22 studies of long-term non-pharmacological weight loss interventions in type 2 diabetes through health behavior changes for 1 to 5 years, the pooled weight loss was a modest $1.7 \mathrm{~kg}$, or $3.1 \%{ }^{34}$. The compelling evidence on modest weight loss in the prevention or delay in type 2 diabetes raised the tantalizing question of whether long-term lifestyle intervention exert beneficial health and cardiovascular outcomes in type 2 diabetes ${ }^{38}$.

Imayama et al. Conducted a randomized controlled trial on overweight/obese postmenopausal women randomly for 12 months and found that a combined diet and exercise intervention resulted in weight loss and had positive effects on health-related quality of life and psychological health which included depression, anxiety and social support ${ }^{39}$. While, Wycherley etal. conducted in a parallel design, a study on 106 obese men and women with type 2 diabetes who were randomized to a prescriptive 16-week caloric restricted diet (6,000-7,000 $\mathrm{kJ} /$ day), with supervised resistance exercise training ( $\mathrm{n}$ $=65$ ) or without supervised resistance exercise training $(\mathrm{n}=41$ ) (three times per week) and found that structured caloric restricted diet with or without resistance exercise training improves body weight, glycated hemo- obin, diabetes-specific emotional distress and qualty of life questionnaire in overweight and obese patients with type 2 diabetes ${ }^{40}$. Moreover, Faulconbridge etal. studied the response of depression symptom to changes in body weight and stated that intentional weight loss is often accompanied by improvements in mood of depressed individuals ${ }^{41}$.

Our results revealed that BMI and serum leptin were significantly decreased upon weight loss among obese type 2 diabetes patients. Our findings were consistent with Sartorio and colleagues who proved that the circulating levels of leptin have been shown to decrease in response to decreases in energy availability ${ }^{42}$, also Volek and colleagues suggested that significant decreases in leptin occur as part of an 8-week weight loss program ${ }^{43}$, which similarly occurred in the present study.

Leptin is recognized to play an integral role in endocrine regulation of metabolism. The higher serum leptin level in obese subjects was clearly evident to be decreased during calorie restriction ${ }^{44}$. Reduction in leptin concentrations is not only due to decreased body fat mass but potentially through an increase in leptin sensitivity ${ }^{45}$. Moreover, leptin signaling to brain stem hypothalamic pathways potentially increases the brain's motor and autonomic responses to satiety signals, leading to smaller individual meals; reduce cumulative food intake, and a lowers body weight ${ }^{46}$. The decrease in serum leptin level after weight reduction was correlated with reduction in $\mathrm{BMI}^{47}$. Weight loss and decrease in BMI in obese diabetes patients was due to enhanced fat oxidation ${ }^{48}$.

Finally, the results of the present study regarding $\mathrm{HO}$ MA-IR showed that weight loss resulted in decrease in HOMA-IR, this result confirmed by Younger and colleagues reported that increased physical activity leads to improvement in insulin resistance and increase in muscle oxidative capacity which are likely contribute to the beneficial effects of exercise training on insulin action ${ }^{49}$. Also, Kriska and colleagues confirmed that physical activity in obese non-insulin dependent diabetes mellitus decreased blood glucose level through improving insulin sensitivity and decreasing deposition of total fat and intra-abdominal fat. Also, physical activity is negatively associated with insulin concentration as a defense mechanism ${ }^{50}$. However, Roland and colleagues stated that exercise training improves insulin sensitivity 
and glycemic control, increases muscle mass, strength 4. Lau DCW. "Let's take control of diabetes. Now" and endurance ${ }^{51}$. Also, Sato and colleagues and Short et Why and How? Can J Diabetes 2010; 34:317-319.

al. found that physical exercise promotes utilization and 5. DePablos-Velasco P, Salguero-Chaves E, Mata-Poyo lowering of blood glucose. This improvement in insulin J, DeRivas-Otero B, García-Sánchez R, Viguera-Ester action was attributed to the increase in insulin sensitive P. Quality of life and satisfaction with treatment in subglucose transporter on the plasma membrane and oxi- jectswith type 2 diabetes: Results in Spain of the PAN dative enzymes in skeletal muscle ${ }^{52,53}$. While, Albu and ORAMA study. Endocrinol Nutr 2014; 61(1):18---26

colleagues mentioned that lifestyle modifications with 6. Lau D. New insights in the prevention and early diet and exercise are essential part of the management management of type 2 diabetes. Can J Diabetes 2011; of the diabetes obese patient as weight loss leads to im- 35:239-41.

provement in the glucose tolerance, insulin sensitivity, 7. Sharma A, Lau D. Obesity and Type 2 Diabetes Melreductions in lipid levels ${ }^{54}$. Weight reduction program litus. Can J Diabetes 2013; 37: 63-64.

consisted of diet restriction and exercise which was 8. Defronzo R. A new paradigm for the treatment of conducted on thirty-five obese NIDDM patients for type 2 diabetes mellitus. Diabetes 2009; 58:773-95

twelve weeks (diet restriction and exercise) induced sig- 9. Sarwar N, Gao P, Seshasai SR, Gobin R, Kaptoge nificant reductions in body weight, serum leptin levels, S, Di Angelantonio E, etal. Diabetes mellitus, fasting improvements in lipoprotein profile, insulin sensitivity blood glucose concentration, and risk of vascular disand glucose control ${ }^{55}$. Energy restriction resulting in ease: a collaborative meta-analysis of 102 prospective even modest weight loss suppresses endogenous cho- studies. Lancet 2010; 375:2215-22.

lesterol synthesis which leads to a decline in circulating 10. Simon G, Von Korff M, Saunders K, Miglioretti D, lipid concentrations and as a result increased insulin Crane P, van Belle G, et al. Association between obesity sensitivity $^{5,57}$. Through decreasing deposition of total and psychiatric disorders in the US adult population. fat and intra-abdominal fat ${ }^{58}$.

\section{Conclusion}

Weight loss because of aerobic exercise training and dietary measures can be considered as methods of choice for psychological wellbeing and biochemical modulation in obese type 2 diabetes patients.

\section{Acknowledgmen}

The Deanship of Scientific Research (DSR), King Abdulaziz University, Jeddah, funded this project, under grant no. (58/142 / 1434). The authors, therefore, acknowledge with thanks DSR technical and financial support.

\section{References}

1. Finucane M, Stevens G, Cowan M, et al. National, regional, and global trends in body-mass index since 1980: systematic analysis of health examination surveys and epidemiological studies with 960 country-years and 9.1 million participants. Lancet 2011; 377:557-67.

2. Whiting D, Guariguata L, Weil C, et al. IDF diabetes atlas: global estimates of the prevalence of diabetes for 2011 and 2030. Diabetes Res Clin Pract 2011; 94:311-21. 3. McCrimmon R, Ryan C, Frier B. Diabetes and cognitive dysfunction. Lancet 2012; 379: 2291-99.
Arch Gen Psychiatry 2006; 63:824-830.

11. Mather A, Cox B, Enn M, Sareen J. Associations of obesity with psychiatric disorders and suicidal behavors in a nationally representative sample. J Psychosom Res 2009; 66:277-285

12. Petry N, Barry D, Pietrzak R, Wagner J. Overweight and obesity are associated with psychiatric disorders: results from the National Epidemiologic Survey on Alcohol and Related Conditions. Psychosom Med 2008; 70:288-297.

13. Pine D, Cohen P, Brook J, Coplan J. Psychiatric symptoms in adolescence as predictors of obesity in early adulthood: a longitudinal study. Am I Public Healt 1997; 87:1303-1310.

14. Stice E, Presnell K, Shaw H, Rohde P. Psychological and behavioral risk factors for obesity onset in adolescent girls: a prospective study. J Consult Clin Psychol 2005; 73:195-202.

15. Murphy J, Horton N, Burke J, Monson R, Laird N, Lesage A, et al. Obesity and weight gain in relation to depression: findings from the Stirling County Study. Int Obes 2009; 33:335-341.

16. Herva A, Laitinen J, Miettunen J, Veijola J, Karvonen J, Läksy K, et al. Obesity and depression: results from the longitudinal Northern Finland 1966 Birth Cohort Study. Int J Obes 2006; 30:520-527.

17. Roberts R, Deleger S, Strawbridge W, Kaplan G.
Prospective association between obesity and depression: evidence from the Alameda County Study. Int Obes Relat Metab Disord 2003; 27:514-521.

18. Narayan K, Boyle J, Thompson T, Gregg E, Williamson D. Effect of BMI on lifetime risk for diabetes in the U.S. Diabetes Care. 2007; 30(6):1562-6.

19. Lau D. Fight diabetes: the Tsunami of non-communicable diseases. Can I Diabetes 2009; 33:348-349.

20. American Diabetes Association. Executive Summary. Standards of medical care in diabetes 2013. Diabetes Care 2013; 36:S4-S10.

21. American Diabetes Association. Diagnosis and Classification of Diabetes Mellitus. Diabetes Care 2013; 36:S67-74

22. Wu T, Gao X, Chen M, van Dam RM. Long-term effectiveness of diet-plus exercise interventions vs. diet-only interventions for weight loss: a meta-analysis. Obes Rev 2009; 10:313-23.

23. Deed G. Integrative care of type 2 diabetes mellitus. Advances in Integrative Medicine 2014; 1: 55-58.

24. Palmeira A, Branco T, Martins S, Minderico C, Silva $\mathrm{M}$, Vieira P, etal. Change in body image and psychological well-being during behavioral obesity treatment: Associations with weight loss and maintenance. Bod Image 2010; 7(3): 187-193.

25. Thompson WR, Gordon NF, Pescatello LS. ACSM's guidelines for exercise testing and prescription: Hubsta Ltd 2009.

26. Sciacqua A, Candigliota M, Ceravolo R, Scozzafava A, Sinopoli F, Corsonello A, Sesti G,Perticone F. Weight loss in combination with physical activity improves endothelial dysfunction in human obesity. Diabetes Care 2003; 26: 1673-1678.

27. World Health Organization. Diet, nutrition, and the prevention of chronic diseases. World Health Organ Tech Rep Ser 1990; 797:1-204.

28. Murakami T, Horigome H, Tanaka K, Nakata Y, Ohkawara K, Katayama Y, Matsui A. Impact of weight reduction on production of platelet-derived microparticles and fibrinolytic parameters in obesity. Thrombosis Research 2007; 119: 45-53.

29. Stunkard A, Rush J. Dieting and depression re-examined a critical review of reports of untoward responses during weight reduction for obesity. Annals of Internal Medicine 1974; 81: 526-533.

30. Bryan J, Tiggemann, M. The effect of weight-loss dieting on cognitive performance and psychological well-being in overweight women. Appetite 2001; 36:147-156.
1. Wing R, Blair E, Marcus M, Epstein L, Harvey J. Wer-long weight loss treatment for obese patients with type II diabetes: does including an intermitten very-low-calorie diet improve outcome? American Journal of Medicine 1994; 97, 354-362.

32. Butryn M, Wadden T. Treatment of overweight in children and adolescents: does dieting increase the ris of eating disorders? International Journal of Eating Disorders 2005; 37: 285-293.

33. Werrij M, Mulkens S, Hospers H, Smits-de B, Jansen, A. Dietary treatment for obesity reduces BMI and imA ves eating psychopathology, selfesteem, and mood. Netherlands Journal of Psychology 2008; 64:8-14.

34. Pi-Sunyer X, Blackburn G, Brancati F, Bray G Bright R, Clark J, et al. Reduction in weight and cardiovascular disease risk factors in individuals with type 2 diabetes: one-year results of the look AHEAD trial Diabetes Care. $2007 ; 30(6): 1374-83$.

35. Snel M, Sleddering M , vd Peijl I, Romijn J, Pijl H , Meinders A, Jazet I .Quality of life in type 2 diabetes mellitus after a very low calorie diet and exercise. European Journal of Internal Medicine 2012; 23 :143-149.

36. Jazet I, de Craen A, van Schie E, Meinders A.Sustained beneficial metabolic effects 18 months after a 30 day very low calorie diet in severely obese, insulin-treated patients with type 2 diabetes.Diabetes Research and Clinical Practice 2007; 77 : 70-76.

37. Grave R, Calugi S, Petroni M, Di Domizio S, Marchesini G. Weight management, psychological distress and binge eating in obesity. A reappraisal of the problem. Appetite 2010; 54 : 269-273.

38. Lau DC, Teoh H. Benefits of Modest Weight Loss on the Management of Type 2 Diabetes Mellitus. Can Diabetes 2013; : 128-134.

39. Imayama I, Alfano C, Kong A, Foster-Schubert K Bain C, Xiao L, etal. Dietary weight loss and exercise interventions effects on quality of life in overweight/ obese postmenopausal women: a randomized controlled trial. International Journal of Behavioral Nutrition and Physical Activity 2011, 8:118-129.

40. Wycherley T, Clifton P, Noakes M, Brinkworth G. Weight loss on a structured hypocaloric diet with or without exercise improves emotional distress and quality of life in overweight and obese patients with type 2 diabetes. Journal of Diabetes Investigation 2014; 5:94-98.

41. Faulconbridge L, Wadden T, Rubin R, Walkup A, Fabricatore A, Coday M, et al. One-year changes in weight and symptoms of depression in depressed vs. non-depressed individuals in the Look AHEAD study. Obesity 2009; 17 suppl 2:576 
42. Sartorio A, Agosti F, Resnik M, Lafortuna CL. Effects of a 3-week integrated body weight reduction program on leptin levels and body composition in severe obese subjects. J Endocrinol Invest 2003; 26:250-256.

43. Volek JS, Gomez AL, Love DM, Weyers AM, Hesslink R Jr, Wise JA, Kraemer WJ. Effects of an 8-week weight-loss program on cardiovascular disease risk factors and regional body composition. Eur J Clin Nutr 2002; 56:585-592.

44. Harder H, Dinesen B, Astrup A. The effect of a rapid weight loss on lipid profile and glycemic control in obese type 2 diabetic patients. Int J Obes Relat Metab Disord 2004; 28:180-192.

45. Chu N, Stampfer M, Splegelman D. Dietary and lifestyle factors in relation to plasma leptin concentrations among normal weight and overweight men .Int J Obes Relat Metab Dis 2001; 25:106-114.

46. WHO. Obesity. Preventing and managing the global epidemic. WHO technical report series 894. Geneva, Switzerland: WHO 2000 : 5-37.

47. Sandoval D, Davis S. Leptin, Metabolic control and regulation. J Diabetes Complications 2003; 17: 108 - 13.

48. Compbell L, Rossner S. Management of obesity in patients with type 2 diabetes. Diabetes Med 2001; 18:345-354.

49. Youngren J, Keen S, Kulp J. Enhanced muscle insulin receptor autophosphorylation with short term aerobic exercise training. Am J Physiol Endocrinal Metab 2001; 280:528-533.

50. Kriska A, Pereira M, Hanson R. Association of physical activity and serum insulin concentration in two populations at high risk for type 2 diabetes .Diabetes Care 2001; 24:1175-1182.

51. Roland J, Glen P, David H, Carmen C. Physical activity, exercise and type 2 diabetes. Diabetes Care 2004; 27:2518-2539.

52. Sato Y, Masaru N, Naoya N, Takashi F. Physical exercise improves glucose metabolism in lifestyle-related diseases. Experimental Biology and Medicine 2003; 228:1208-1212.

53. Short K, Vittone J, Bigelow M, Proctor D. Impact of aerobic exercise training on age related changes in insulin sensitivity and muscle oxidative capacity. Diabetes 2003; 52:1888-1896.

54. Albu J, Raja- Khan N. The management of the obese diabetic patient. Prim Care 2003; 30:457 91.

55. Ruche R, McDonald R. Use of antioxidants nutrients in the prevention and treatment of type 2 diabetes. J Coll Nutr 2001; 20: S 363 - S 369.

56. Di Buono M, Hannah JS, Katzel LL, Jones PJ. Weight loss due to energy restriction suppresses cholesterol biosynthesis in overweight, mildly hypercholesterolemic men. J Nutr 1999; 129: 1545 - 8.

57. Lamarche B, Despress J, Pouliot MC, Moorjani S, Lupien P, Jheriault G, Tremblay A, Nadeau A, Bouchard C. Is body fat loss a determinant factor in the improvement of carbohydrate and lipid metabolism following aerobic exercise training in obese women?. Metabolism 1992; 41: 1249-1256.

58. Kriska A, Pereira M, Hanson R. Association of physical activity and serum insulin concentration in two populations at high risk for type 2 diabetes .Diabetes Care 2001; 24:1175-1182. 